\title{
PENINGKATAN KUALITAS PELAYANAN AKTA KELAHIRAN MENGGUNAKAN PENDEKATAN SIX SIGMA DI DINAS KEPENDUDUKAN DAN PENCATATAN SIPIL KABUPATEN PELALAWAN
}

\author{
Denny Astrie Anggraini, Satriardi \\ Program Studi Teknik Industri Universitas Muhammadiyah Riau \\ Jalan Tuanku Tambusai Ujung (Samping SKA) Pekanbaru \\ *E-mail :d_nny0204@yahoo.com
}

\begin{abstract}
Abstrak
Kepuasan masyarakat merupakan hal yang penting dilakukan oleh pemberi pelayanan publik salah satunya Dinas Kependudukan dan Pencatatan Sipil (Disdukpencapil) Kabupaten Pelalawan. Oleh karena itu penelitian ini dilakukan untuk mengidentifikasi variabel yang mempengaruhi kualitas pelayanan, mengukur tingkat kualitas layanan yang diberikan saat ini dan memberikan rekomendasi tindakan perbaikan dalam pembuatan Akta Kelahiran. Pendekatan yang digunakan yaitu dengan menggunakan Six Sigma. Pada tahap define dilakukan penyebaran kuesioner terbuka, diperoleh 17 variabel yang mempengaruhi kualitas pelayanan. Selanjutnya dirancang dan disebar kuesioner tertutup. Setelah dinyatakan Valid dan Reliabel maka penyebaran kuesioner sebenarnya dilakukan untuk mengetahui tingkat kepuasan dan kepentingan yang dirasakan masyarakat saat ini. Pada tahap Measure dilakukan pengukuran kondisi saa tini dengan melihat tingkat sigma dan menggunakan diagram IS. Terdapat 8 variabel berada pada kuadran Attention dan 9 variabel berada pada kuadran Bravo.Variabel yang berada pada kuadran Attention dicari akar penyebab masalah yang umumnya disebabkan oleh faktor SDM. Pada tahap Analyze digunakan metode 5W-1H. Tahap Improve diketahui elemen-elemen yang terkait dalam pelayanan pembuatan Akta Kelahiran yaitu pimpinan, staf dan masyarakat. Kemudian SOP dibakukan dan dioptimalkan pelaksanaanya. Pada tahap Control dilakukan pengawasan pada setiap proses agar sesuai dengan SOP yang sudah dibakukan.
\end{abstract}

Kata kunci : DMAIC, Diagram IS, Kualitas Layanan, Six sigma.

\section{PENDAHULUAN}

Pada era otonomi daerah ini pemda di tuntut untuk dapat memberikan pelayanan yang lebih kepada masyarakat dalam berbagai bidang utamanya adalah bidang pelayanan publik salah satunya adalah pelayanan dibidang kependudukan. Berdasarkan Peraturan Daerah Nomor 7 Tahun 2008 tentang Susunan Organisasi dan Tata Kerja Dinas Daerah Kabupaten Pelalawan, Pemda kabupaten Pelalawan membentuk tersendiri Dinas Kependudukan dan Catatan Sipil yang sebelumnya bergabung dari Dinas Transmigrasi dan Kependudukan. Dinas Kependudukan dan Catatan sipil (DISDUKPENCAPIL) adalah kantor tempat informasi mengenai data kependudukan yang akurat dan sangat dibutuhkan dalam aktifitas program pembangunan yang dalam tugas kesehariannya ada pelayanan untuk blanko kartu keluarga (KK), blanko Kartu Tanda Pendudukan (KTP), Akta kelahiran, Akta Perkawinan (Non Muslim), Akta Perceraian, Akta Kematian, Pengesahan dan Pengakuan Anak.

Pembentukan Dinasini bertujuan untuk memudahkan masyarakat mengurus segala sesuatu yang berkaitan dengan kependudukan. Oleh karena itu Dinas Kependudukan dan Catatan Sipil diharapkan dapat memberikan pelayanan umum yang baik kepada masyarakat.

Tujuan mengadakan penelitian ini adalah sebagai berikut:

1. Mengidentifikasi variabel yang mempengaruhi kualitas pelayanan pembuatan Akta Kelahiran.

2. Mengukur tingkat kualitas layanan yang diberikan saat ini.

3. Memberikan rekomendasi tindakan perbaikan dalam proses pelayanan pembuatan Akta Kelahiran. 


\section{LANDASAN TEORI}

\section{A. Kualitas}

Kata kualitas memiliki berbagai makna.Banyak pakar ahli kualitas tingkat.Kualitas menurut ISO (Gaspersz, 2003) didefinisikan sebagai derajat atau tingkat karakteristik yang melekat pada produk yang mencakup persyaratan atau keinginan.Arti derajat menandakan bahwa selalu terdapat pcningkatan setiap saat.Sedangkan, karakteristik pada istilah tersebut berarti hal-hal yang dimiliki produk. Dan Dalam ISO 8402 (Quality Vocabulary). Berdasarkan pengertian dasar tentang kualitas di atas, tampak bahwa kualitas selalu berfokus pada pelanggan (customer focused quality).Dengan demikian produk-produk didesain, diproduksi, serta pelayanan diberikan untuk memenuhi keinginan pelanggan.Karena kualitas mengacu pada segala sesuatuyang menentukan kepuasan pelanggan, suatu produk yang dihasilkan baru dapat dikatakan berkualitas apabila sesuai dengan keinginan pelanggan.

\section{B. Metode Six Sigma}

Six Sigma Motorola merupakan suatu metode atau teknik pengendaliandan peningkatan kualitas dramatik yang diterapkan oleh perusahaan Motorola sejak tahun 1986, yang merupakan terobosan baru dalam bidang manajemen kualitas.Motorola dikembangkan dan diterima secara luas oleh dunia industri, karena manajemen industri frustasi terhadap sistem-sistem manajemen kualitas yang ada, yang tidak mampu melakukan peningkatan kualitas secara dramatik menuju tingkat kegagalan nol (zero defect).

Program Six Sigma juga merupakan sistem manajemen kualitas yang memiliki target kinerja dramatik 3,4 DPMO (Defects Per Million Opportunities) atau tingkat kapabilitas proses 6-sigma melalui implementasi program peningkatan terus-menerus (Continuous Improvement Programs). Apabila produkbarang/jasa) diproses pada tingkat kualitas Six Sigma, perusahaan boleh mengharapkan 3,4 kegagalan per sejuta kesempatan (DPMO) atau mengharapkan bahwa 99,99966 persen dari apa yang diharapkan pelanggan.

Tabel 1. Konversi Nilai DPMO Terhadap Tingkat Sigma

\begin{tabular}{|c|c|}
\hline Tingkat Sigma & DPMO \\
\hline 1 & 691462 \\
\hline 1,5 & 500000 \\
\hline 2 & 308508 \\
\hline 2,5 & 158655 \\
\hline 3 & 66807 \\
\hline 3,5 & 22750 \\
\hline 4 & 6210 \\
\hline 4,5 & 1350 \\
\hline 5 & 233 \\
\hline 5,5 & 32 \\
\hline 6 & 3,4 \\
\hline
\end{tabular}

Sumber : Vincent Gasperz, 2002

Menurut Pete Pande dan Larry Holpp, 2003, dalam bukunya Berpikir Cepat Six Sigma, Six Sigma adalah sebuah cara pintar untuk mengelola sebuah bisnis atau departemen. Proyek Six Sigma merupakan Suatu strategi dan sistem yang secara terusmenerus menelusuri dan memperbaharui kebutuhan pelanggan, aktivitas pesaing, perubahan pasar, dan lain-lain .Dengan demikian, program Six Sigma menjadi suatu system" Voice of Customer (VOC)", Suatu analisis kinerja dan standar-standar 
pelayanan berdasarkan pada kepentingan relatif terhadap pelanggan dan dampaknya pada strategi bisnis. Terdapat enam aspek kunci yang perlu diperhatikan dalam aplikasi konsep Six Sigma, yaitu : (Gasperz, 2002)

1. Identifikasi pelanggan anda,

2. Identifikasi produk anda,

3. Identifikasi kebutuhan anda dalam memproduksi produk untuk pelanggan.

4. Definisikan proses anda.

5. Hindari kesalahan dalam proses anda dan hilangkan semua pemborosan.

6. Tingkatkan proses anda secara terus-menerus menuju target Six Sigma.

DMAIC merupakan proses untuk peningkatan terus-menerus menuju Six Sigma. DMAIC dilakukan secara sistematik, berdasarkan ilmu pengetahuan danfakta (systematic, scientific and fact based). Proses closed-loop ini (DMAIC) menghilangkan langkah-langkah proses yang tidak produktif sering berfokus pada pengukuranpengukuran baru dan menerapkan teknologi untuk peningkatan kualitas menuju target Six Sigma. Dengan mengikuti proses ini sebuah proses dengan lima langkah yang fleksibel namun powerfull untuk membuat perbaikan yang dapat tercapai dan dijalankan.Mempertahankan perubahan membuat perubahan terus berlanjutmerupakan kunci final bagi pendekatan pemecahan masalah yang lebih memberikan pencerahan.

\section{METODOLOGI PENELITIAN}

Metodologi yang digunakan dalam penelitian ini terdiri dari beberapa tahap, yaitu:

a. Tahap Studi Pendahuluan, meliputi :

Melihat permasalahan apa yang terjadi dalam instansi yang menjadi objek penelitian,

b. Tahap Perumusan Masalah, meliputi :

Merumuskan dari keseluruhan masalah yang terdapat dalam objek penelitian,

c. Studi Literatur, meliputi :

Melakukan persiapan penelitian dengan teori dan konsep,

d. Tahap Pengumpulan Data, meliputi :

1. Wawancara digunakan untuk mengingatkan interviewer mengenai aspek-aspek apa yang harus dibahas,

2. Observasi merupakan kegiatan dengan cara turun langsung untuk melihat dan mengumpulkan data yang akan digunakan,

e. Tahap Hasil dan Pembahasan, meliputi :

1. Tahap Define.

a. Diagram SIPOC (Supplier, Input, Process, Output, Costumers)

b. Identifikasi Variabel yang Mempengaruhi Kualitas Pelayanan

c. Perancangan Kuesioner Tertutup

d. Penyebaran Kuesioner Pretest atau Pendahuluan

e. Uji Validitas dan Uji Reliabilitas

f. Penyebaran kuesioner sebenarnya

2. Tahap Measure

a. Pengukuran kondisi saat Ini

b. Mencari Akar Penyebab Permasalahan (Diagram Fishbone)

3. Tahap Analyze

a. Menganalisa permasalahan yang terjadi dengan Metode $5 \mathrm{~W}-1 \mathrm{H}$

4. Tahap Improve

a. Mengimplementasikan Metode Total Integrated Logistics (TIL)

b. Pembakuan SOP dan pengoptimalan pelaksanaan Standar Operation Procedure (SOP)

5. Tahap Control

a. Pengawasan setiap proses harus dilakukan sesuai SOP

\section{f. Tahap Kesimpulan dan Saran}




\section{HASIL DAN PEMBAHASAN}

\section{A. Tahap Define}

Adapun gambar diagram SIPOC pada proses kepengurusan pembuatan Akta Kelahiran di Disdukpencapil Kabupaten Pelalawan adalah sebagai berikut :

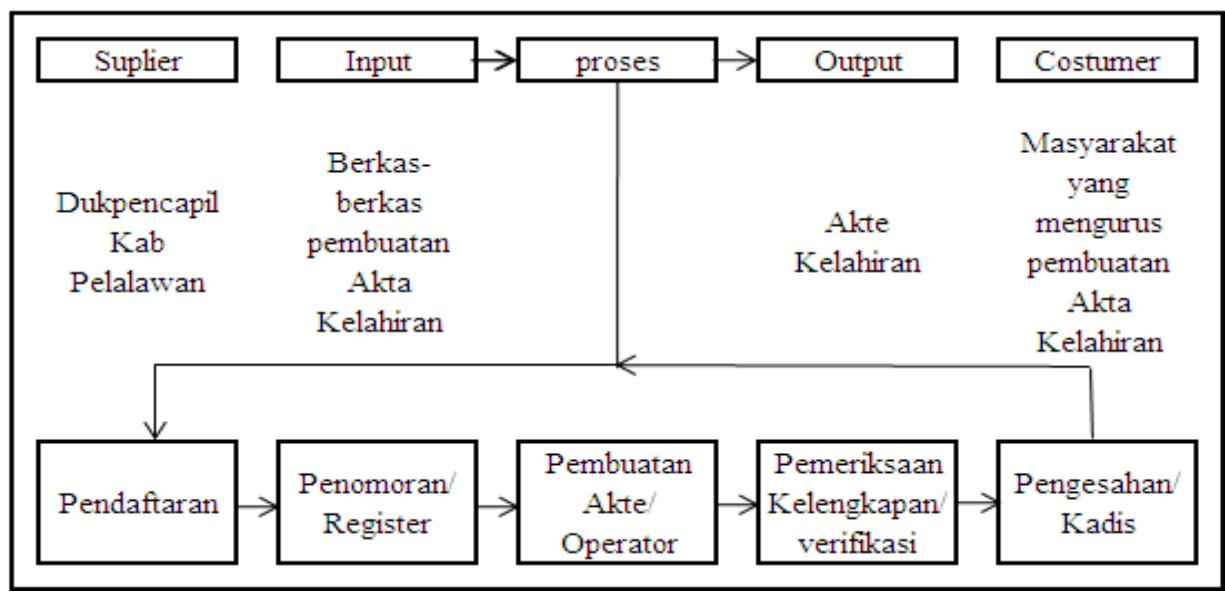

Gambar 1. Diagram SIPOC Prosedur Pelayanan Pembuatan Akta Kelahiran Sumber : Disdukpencapil Kab Pelalawan, 2014

Selanjutnya disebarkan kuesioner terbuka untuk melihat variabel-variabel yang dianggap penting oleh masyarakat yang mempengaruhi kualitas pelayanan dalam pengurusan Akta Kelahiran di instansi, yaitu sebagai berikut :

Tabel 2. Variabel yang Mempengaruhi Kualitas Pelayanan Pembuatan Akta Kelahiran

\begin{tabular}{|c|l|}
\hline No & \multicolumn{1}{|c|}{ Variabel } \\
\hline 1 & Kejelasan prosedur pelayanan \\
\hline 2 & Kejelasan persyaratan pelayanan \\
\hline 3 & Kejelasan petugas pelayanan \\
\hline 4 & Kesopanan dan Keramahan petugas layanan \\
\hline 5 & Kenyamanan dan keamanan lingkungan (gedung, loket, dan fasilitas kerja) \\
\hline 6 & Kemampuan petugas pelayanan \\
\hline 7 & Kedisiplinan petugas pelayanan \\
\hline 8 & Tanggung jawab petugas pelayanan \\
\hline 9 & Kenyamanan masyarakat dalam berhubungan dengan petugas pelayanan \\
\hline 10 & Kecepatan dan ketepatan pelayanan \\
\hline 11 & Respon terhadap keluhan dan saran masyarakat \\
\hline 12 & Kepastian jadwal pelayanan \\
\hline 13 & Keadilan mendapatkan pelayanan \\
\hline 14 & Ketersediaan Akta Kelahiran \\
\hline 15 & Kepastian waktu penyelesaian Akta Kelahiran \\
\hline 16 & Kepedulian petugas pelayanan terhadap masyarakat \\
\hline 17 & Kesungguhan petugas unit pelayanan dalam membantu masyarakat \\
\hline
\end{tabular}

Sumber : Pengumpulan Data, 2014

Variabel di atas dikembangkan menjadi sebuah kuesioner tertutup dan disebarkan kembali ke masyarakat. Hasil penyebaran kuesiner tersebut diuji validitas dan realibilitas. Setelah dinyatakan valid dan reliable maka hasil penyebaran kuesioner tersebut dapat diolah lebih lanjut. 


\section{B. Tahap Measure}

Setelah dilakukan pengukuran dapat diketahui tingkat kepentingan dan kepuasan yang dirasakan masyarakat pada saat ini di Disdukpencapil Kab Pelalawan adalah sebagai berikut :

Tabel 3. Pengukuran Baseline Kualitas pada Tingkat Outcome

\begin{tabular}{|c|c|c|c|c|c|c|c|c|}
\hline $\begin{array}{c}\mathbf{C} \\
\mathbf{T} \\
\mathbf{Q} \\
(\mathbf{1})\end{array}$ & $\begin{array}{c}\text { Rating } \\
\text { Kepen- } \\
\text { tingan } \\
(2)\end{array}$ & $\begin{array}{c}\text { Rating } \\
\text { Kepuasan } \\
\text { (3) }\end{array}$ & $\begin{array}{c}\text { Gap } \\
\text { Terhadap } \\
\text { Kepentingan } \\
\text { Masyarakat } \\
(4)=(2)-(3)\end{array}$ & $\begin{array}{c}\text { Target } \\
\text { Kepuasan } \\
(5)\end{array}$ & $\begin{array}{c}\text { Tingkat } \\
\text { Kepuasan } \\
\text { Sekarang } \\
(6)=[(3) /(5)] \\
x 100 \%\end{array}$ & $\begin{array}{c}\text { DPMO } \\
(7)=(1- \\
(6)) \times 1.000 . \\
000\end{array}$ & $\begin{array}{c}\text { Sigma } \\
\text { (8) }\end{array}$ & $\begin{array}{c}\text { Posisi } \\
\text { Kuadran } \\
\text { IS (9) }\end{array}$ \\
\hline 1 & 3,977 & 4,793 & $-0,816$ & 5,00 & $95,86 \%$ & 41.400 & 3,24 & B \\
\hline 2 & 3,921 & 4,839 & $-0,918$ & 5,00 & $96,78 \%$ & 32.200 & 3,35 & B \\
\hline 3 & 4,287 & 3,356 & 0,931 & 5,00 & $67,12 \%$ & 328.800 & 1,95 & $\mathrm{~A}$ \\
\hline 4 & 4,276 & 3,368 & 0,908 & 5,00 & $67,36 \%$ & 326.400 & 1,95 & $\mathbf{A}$ \\
\hline 5 & $\mathbf{3 , 8 9 7}$ & 4,747 & $-0,85$ & 5,00 & $94,94 \%$ & 50.600 & 3,14 & B \\
\hline 6 & 4,368 & 3,345 & 1,023 & 5,00 & $66,90 \%$ & 331.000 & 1,94 & A \\
\hline 7 & 4,506 & 3,081 & 1,425 & 5,00 & $61,62 \%$ & 383.800 & 1,8 & $\overline{\mathbf{A}}$ \\
\hline 8 & 3,644 & 4,793 & $-1,149$ & 5,00 & $95,86 \%$ & 41.400 & 3,24 & B \\
\hline 9 & 3,954 & 4,793 & $-0,839$ & 5,00 & $95,86 \%$ & 41.400 & 3,24 & B \\
\hline 10 & 4,195 & 3,034 & 1,161 & 5,00 & $60,68 \%$ & 393.200 & 1,78 & $\overline{\mathrm{A}}$ \\
\hline 11 & 3,954 & 4,782 & $-0,828$ & 5,00 & $95,64 \%$ & 43.600 & 3,21 & B \\
\hline 12 & 4,195 & 3,161 & 1,034 & 5,00 & $63,22 \%$ & 367.800 & 1,84 & $\mathbf{A}$ \\
\hline 13 & 3,966 & 4,805 & $-0,839$ & 5,00 & $96,10 \%$ & 39.000 & 3,27 & B \\
\hline 14 & 4,598 & 3,172 & 1,426 & 5,00 & $63,44 \%$ & 365.600 & 1,85 & A \\
\hline 15 & 4,494 & 3,161 & 1,333 & 5,00 & $63,22 \%$ & 367.800 & 1,84 & A \\
\hline 16 & 3,885 & 4,759 & $-0,874$ & 5,00 & $95,18 \%$ & 48.200 & 3,17 & B \\
\hline 17 & 3,921 & 4,724 & $-0,803$ & 5,00 & $94,48 \%$ & 55.200 & 3,1 & B \\
\hline & & & & & & & 2,5829 & \\
\hline
\end{tabular}

Sumber : Pengolahan Data, 2014

\section{Keterangan :}

\section{Kode CTQ :}

1. Kejelasan prosedur pelayanan

2. Kejelasan persyaratan pelayanan

3. Kejelasan petugas pelayanan

4. Kesopanan dan Keramahan petugas pelayanan

5. Kenyamanan dan keamanan lingkungan (gedung, loket, \& fasilitas kerja)

6. Kemampuan petugas pelayanan

7. Kedisiplinan petugas pelayanan

8. Tanggung jawab petugas pelayanan

9. Kenyamanan masyarakat dalam berhubungan dengan petugas pelayanan

10. Kecepatan dan ketepatan pelayanan

11. Respon terhadap keluhan dan saran masyarakat

12. Kepastian jadwal pelayanan

13. Keadilan mendapatkan pelayanan

14. Ketersediaan Akta Kelahiran di Disdukpencapil

15. Kepastian waktu penyelesaian Akta Kelahiran

16. Kepedulian petugas unit pelayanan terhadap masyarakat

17. Kesungguhan petugas unit pelayanan dalam membantu masyarakat

2. Rating kepentingan dan kepuasan menggunakan skala $1-5$, dengan urutan kepentingan : 1 =sangat tidak penting, $2=$ tidak penting, $3=$ cukup, $4=$ penting, $5=$ sangat penting. Dan urutan kepuasan : $1=$ sangat tidak puas, $2=$ tidak puas, $3=$ Cukup, $4=$ puas, $5=$ sangat puas.

3. Target kepuasan dalam program Six Sigma adalah $100 \%$ atau pada skor nilai 5 dalam skala $1-5$. DPMO $=(1$-tingkat kepuasan $) \times 1.000 .000$. Contoh $:$ DPMO $(a)=(1-95.86 \%) \times$ $1.000 .000=(1-0,9586) \times 1.000 .000=41.400$. 
4. Nilai sigma dilihat dari tabel konversi DPMO ke nilai sigma pada lampiran E. Misalnya $\operatorname{DPMO}(\mathrm{a})=41.400$ adalah paling dekat dengan nilai $\mathrm{DPMO}=40,929$ pada tingkat sigma $=$ 3.23 sigma.

5. Berdasarkan diagram IS dibawah ini, rating kepentingan dan kepuasan terhadap kualitas yang ada saat ini berada pada Kuadran A (Attention) adalah kuadran dengan tingkat kepentingan tinggi dan tingkat kepuasan yang rendah dan pada Kuadran B (Bravo) Kuadran dengan tingkat kepentingan yang tinggi dan tingkat kepuasan yang tinggi, sehingga perlu diberikan perhatian khusus pada karakteristik kualitas (CTQ) yang berada pada kuadran A tersebut.

\section{Diagram Importance Satisfaction}

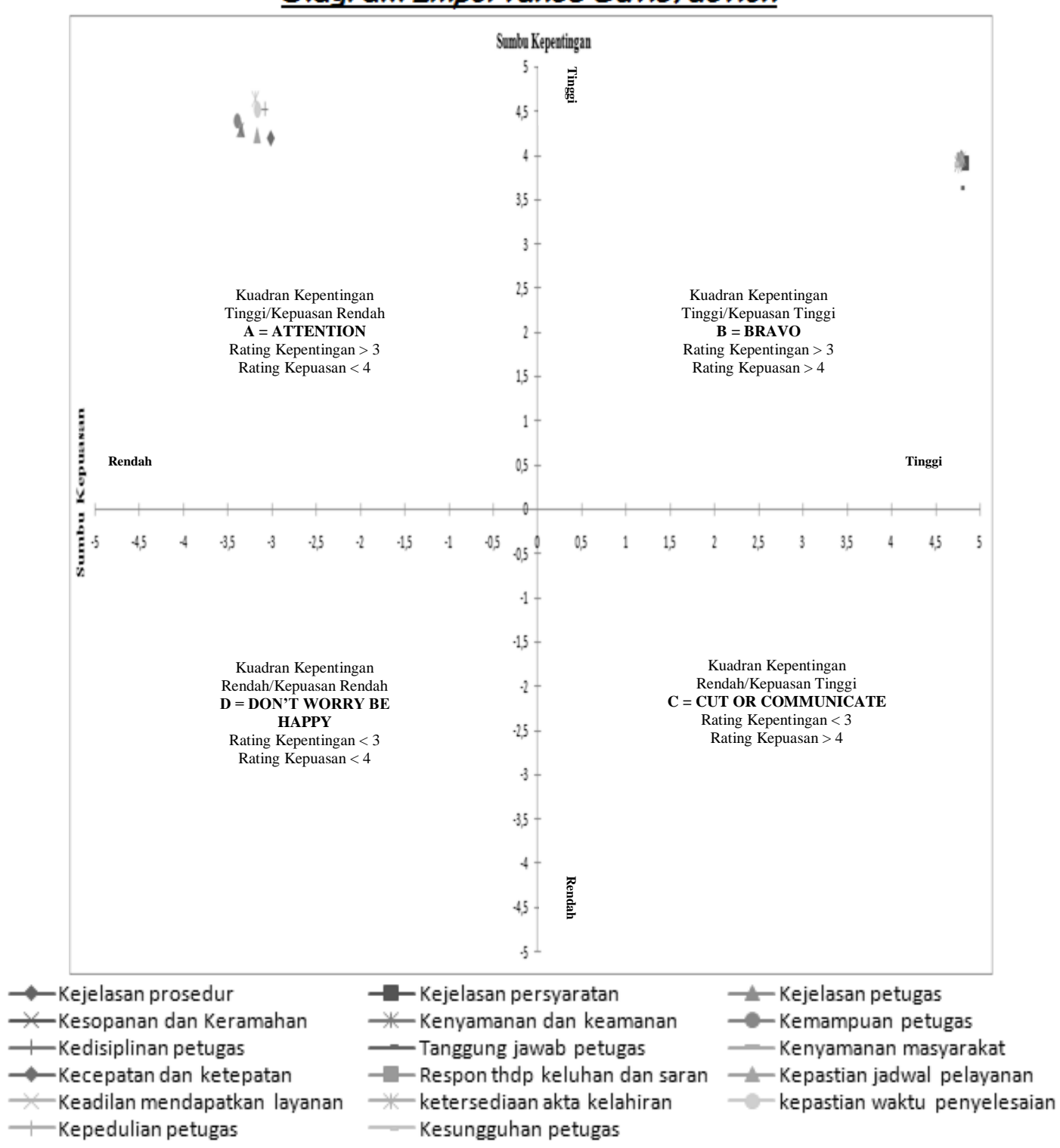

Gambar 2. Diagram IS (Importance-Satisfaction)

Sumber : Vincent Gasperz, 2002 
Akar penyebab permasalahan dari variable yang terletak pada kuadran A (Attention), antara lain sebagai berikut :

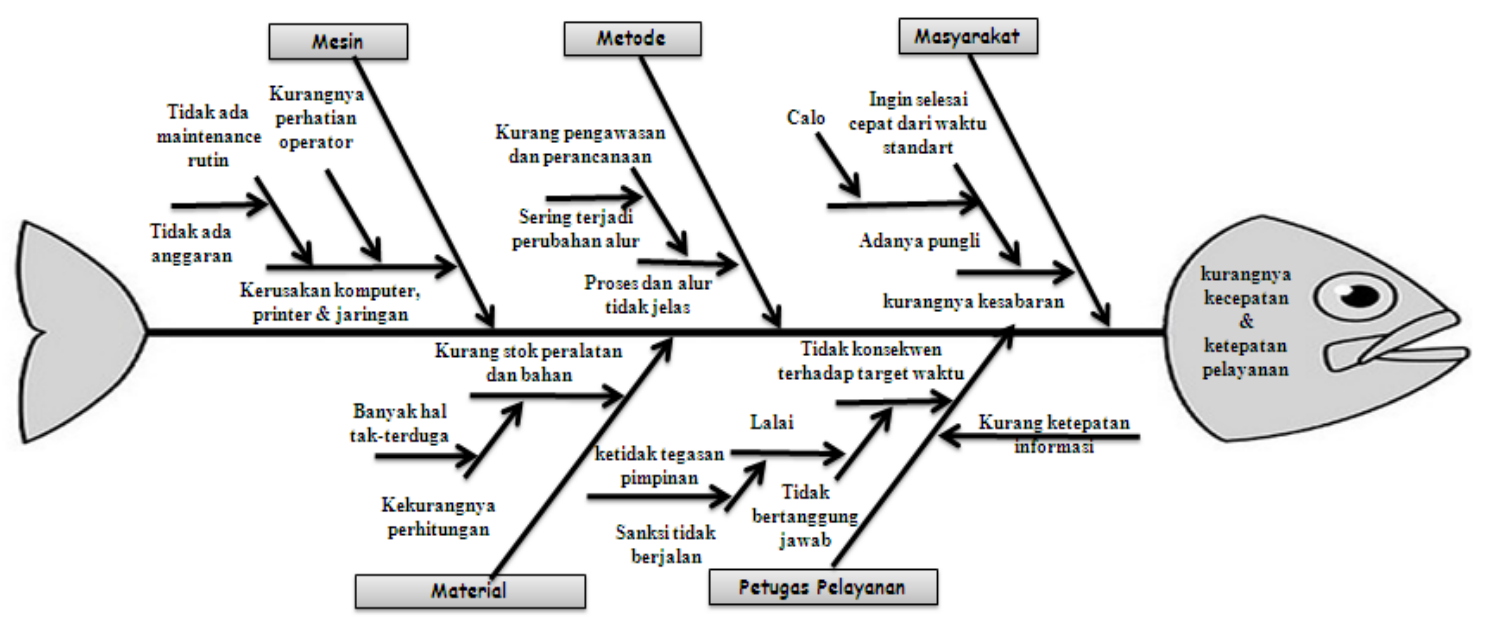

Gambar 3. Diagram FishboneKurangnya kecepatan dan ketepatan pelayanan Sumber : Pengolahan Data, 2014

\section{Tahap Analyze}

Tahapan ketiga dari implementasi six sigma ini adalah tahap analisa dengan menggunakan $5 \mathrm{~W}+1 \mathrm{H}$ sebagai berikut :

\begin{tabular}{|c|c|c|}
\hline \multicolumn{2}{|r|}{$5 W-1 H$} & Jawaban \\
\hline What & $\begin{array}{l}\text { Apa yang terjadi } \\
?\end{array}$ & Kurangnya kecepatan dan ketepatan pelayanan \\
\hline Why & Mengapa terjadi? & $\begin{array}{l}\text { - Petugas tidak konsekwen terhadap target waktu } \\
\text { - Kurangnya ketepatan informasi } \\
\text { - Petugas yang tidak bertanggung jawab } \\
\text { - Adanya kelalaian petugas } \\
\text { - Sanksi hukup pada petugas yang tidak berjalan } \\
\text { - Kurangnya ketegasan pimpinan } \\
\text { - Kurangnya stok persedian pada bahan dan peralatan } \\
\text { - Kekurangan perhitungan } \\
\text { - Banyaknya hal-hal yang tidak terduga } \\
\text { - Kurangnya sifat sabar oleh masyarakat } \\
\text { - Terjadinya pungli oleh petugas lain } \\
\text { - Ingin selesai cepat dari standart } \\
\text { - Adanya pungli } \\
\text { - Adanya calo dalam pengurusan } \\
\text { - Proses dan alur pada metode yang tidak jelas } \\
\text { - Sering terjadinya perubahan alur } \\
\text { - Kurangnya pengawasan dan perencanaan } \\
\text { - Kerusakan pada komputer,printer dan jaringan } \\
\text { - Kurangnya perhatian dari operator } \\
\text { - Tidak adanya maitenance rutin } \\
\text { - Tidak ada anggaran }\end{array}$ \\
\hline Where & Dimana terjadi ? & $\begin{array}{l}\text { Mulai dari pendaftaran, penomoran, register, operator, } \\
\text { verifikasi sampai dengan pengesahan dan pengambilan } \\
\text { Akta Kelahiran }\end{array}$ \\
\hline
\end{tabular}




\begin{tabular}{|c|c|c|}
\hline When & Kapan terjadi? & Pada proses pelayanan \\
\hline Who & $\begin{array}{l}\text { Siapa yang } \\
\text { melakukan? }\end{array}$ & Staf dan Pejabat Disdukpencapil Kab Pelalawan \\
\hline How & $\begin{array}{l}\text { Bagaimana } \\
\text { perbaikan } \\
\text { dilakukan? }\end{array}$ & $\begin{array}{l}\text { - Mempelajari kembali prosedur yang ada } \\
\text { - Mengutamakan kepentingan masyarakat } \\
\text { - Bekerja tanpa pamri } \\
\text { - Memaksimalkan perancanaan dan mekanisme kerja } \\
\text { - Melakukan pengawasan terhadap kualitas pelayanan } \\
\text { dan Memaksimalkan kualitas pelayanan } \\
\text { - Memberikan sanksi disiplin dan teguran kepada } \\
\text { petugas yang melanggar } \\
\text { - Memberikan pelatihan dan pengetahuan kepada } \\
\text { petugas pelayanan } \\
\text { - Memberikan reward terhadap yang berprestasi } \\
\text { sebagai tauladan }\end{array}$ \\
\hline
\end{tabular}

Sumber : Pengolahan Data, 2014

D. Tahap Improve

Tahapan berikutnya dari implementasi six sigma ini adalah tahap improve dengan menggunakan Total Integrated Logistic (TIL) sebagai berikut :

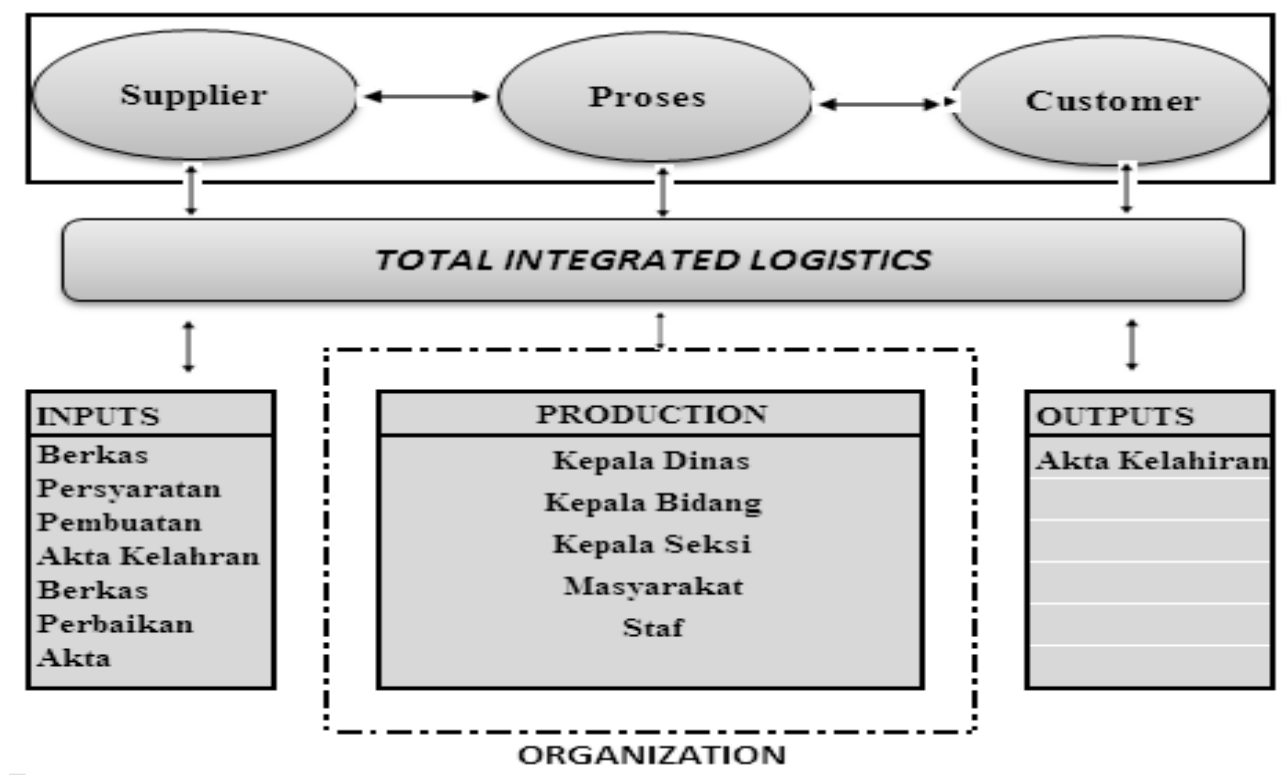

Gambar 4. Keterkaitan Elemen Logistik

Sumber : Analisa Proses, 2014

Pada tahapan sebelumnya, diketahui bahwa permasalahan yang terjadi pada pembuatan Akta Kelahiran yaitu terletak pada sumber daya manusia yang terlibat didalamnya seperti staf, masyarakat sertapejabat Disdukpencapil Kabupaten Pelalawan. Staf, pejabat Disdukpencapil Kab Pelalawan dan Masyarakat itu merupakan elemen-elemen yang sangat menentukan baik atau buruknya kualitas pelayanan.Oleh karena itu, agar dapat meningkatkan kualitas pelayanan harus dilakukan pengintegrasian dari seluruh elemen-elemen logistik tersebut.

Prosedur kerja sederhana untuk memperbaiki dan meningkatkan kualitas pelayanan bagi semua elemen-elemen logistik SDM yang terlibat yaitu: 
PENDAFTARAN (pelayanan penerimaan bahan)

a. Menyediakan formulir untuk pelaporan peristiwa kelahiran

b. Menyeleksi bahan persyaratan permohonan Akta Kelahiran

c. Menyiapkan tanda terima bahan permohonan Akta Kelahiran

d. Menyiapkan dan mengisi formulir permohonan bagi kelahiran yang melampaui batas 60 (enam puluh) hari

e. Menyiapkan hasil kelengkapan bahan dan persyaratan permohonan kelahiran dan dilanjutkan kebagian registrasi

\section{PEMBUKUAN PENOMORAN DAN REGISTER BAHAN}

a. Menerbitkan nomor Akta Kelahiran sesuai urutan bahan dari pendaftaran

b. Melaksanakan penomoran bahan yang diterima dan memasukkan ke buku lintang

c. Meregistrasi bahan dan mencatat kembali ke buku register daftar kelahiran

d. Menyerahkan bahan yang sudah dinomori kepada operator

\section{PEMBUATAN AKTA KELAHIRAN/OPERATOR}

a. Mengimput /mengetik Akta Pencatatan Sipil sesuai dengan bahan yang sudah dinomori dan di registrasi oleh petugas penomoran

b. Meneliti hasil ketikan yang sudah dikerjakan

c. Menyerahkan Akta yang sudah di imput print putih kepada tim verifikasi dan ke absahan untuk ditindak lanjuti

d. Mengetik kembali bahan Akta yang sudah di verifikasi

e. Menyerahkan Akta kepada tim verifikasi

\section{PEMERIKSAAN KELENGKAPAN ATAU VERIFIKASI}

a. Meneliti dengan cermat atas redaksional, kelengkapan bahan, keabsahan bahan dan kebenaran fakta sesuai dengan peraturan dan perundang-undangan yang berlaku

b. Meneliti ulang terhadap keabsahan bahan dan ketikan yang sudah dilaksanakan oleh operator

c. Mengesahkan bahan yang sudah diseleksi dan dikerjakan oleh petugas sebelumnya dalam bentuk pengesahan di stempel serta ditandatangani

d. Setelah menerima perbaikan oleh operator melanjutkan bahan tersebut untuk ditanda tangani oleh kepala dinas

e. Menerima kembali atas laporan kesalahan pengetikan dan kesalahan lainya oleh pelapor

\section{PENGESAHAN KEPALA DINAS}

a. Tanda tangan oleh Kepala Dinas yang menjadi tahapan terpenting terhadap keabsahan Akta Kelahiran

\section{FINAL CHECKING (PENGARSIPAN)}

a. Menyerahkan Akta Kelahiran kepada yang bersangkutan sesuai dengan tanda terima yang disampaikan oleh pelapor

b. Menandatangani berita acara serah terima Akta Kelahiran yang diserahkan kepada yang bersangkutan

c. Menginventarisir bahan bahan yang akan diarsipkan pada buku inventaris arsip dalam pengarsipan

d. Menyusun berkas sebagai arsip untuk disimpan sebagai arsip kantor Disdukpencapil Kab Pelalawan

Agar SOP dapat dijalankan dengan optimal maka setiap elemen yang terkait harus benar-benar menyadari tugas dan tanggung jawabnya masing-masing sehingga peningkatan kualitas pelayanan dalam pembuatan Akta Kelahiran akan menjadi lebih baik dari sebelumnya. 


\section{E. Tahap Improve}

TahapPengendalian(control) merupakan tahap operasional terakhir dalam proyek peningkatan kualitas Six Sigma, membuat rencana dan desain pengukuran agar hasil yang sudah baik dari perbaikan tim bisa berkesinambungan yaitu dengan selalu memonitor dan mengkoreksi, bila sudah mulai menurun maka dilakukan perbaikan lagi. Pada tahapan terakhir ini hasil-hasil dari peningkatan kualitas pelayanan disdukpencapil Kab Pelalawan di dokumentasikan dan disebarluaskan praktek-praktek terbaik yang sukses dalam meningkatkan proses distandarisasikan dandijadikan pedoman kerja standar.

\section{KESIMPULAN DAN SARAN}

\section{A. Kesimpulan}

Berdasarkan penelitian perhitungan dan analisa yang dilakukan ada beberapa kesimpulan yang diperoleh, yaitu sebagai berikut :

1. Setelah dilakukan analisa maka didapatkan variabel yang mempengaruhi kualitas pelayanan pada proses pembuatan Akta Kelahiran dapat dilihatsebagai berikut:

1. Kejelasan prosedur pelayanan

2. Kejelasan persyaratan pelayanan

3. Kejelasan petugas pelayanan

4. Kesopanan dan Keramahan petugas pelayanan

5. Kenyamanan dan keamanan lingkungan (gedung, loket, \& fasilitas kerja)

6. Kemampuan petugas pelayanan

7. Kedisiplinan petugas pelayanan

8. Tanggung jawab petugas pelayanan

9. Kenyamanan masyarakat dalam berhubungan dengan petugas pelayanan

10. Kecepatan dan ketepatan pelayanan

11. Respon terhadap keluhan dan saran masyarakat

12. Kepastian jadwal pelayanan

13. Keadilan mendapatkan pelayanan

14. Ketersediaan Akta Kelahiran di Disdukpencapil

15. Kepastian waktu penyelesaian Akta Kelahiran

16. Kepedulian petugas unit pelayanan terhadap masyarakat

17. Kesungguhan petugas unit pelayanan dalam membantu masyarakat

2. Dalam melakukan pengukur tingkat kualitas layanan yang diberikan saat ini diketahui bahwa sebagian karakteristik kualitas yang digunakan berada pada kuadran A (Attention) yaitu kuadran dengan tingkat kepentingan tinggi dan tingkat kepuasan yang rendah sehingga perlu perhatian khusus terhadap semua karakteristik kualitas yang berada pada kuadran A, yaitu :

1. Kejelasan petugas pelayanan

2. Kesopanan dan Keramahan petugas pelayanan

3. Kemampuan petugas pelayanan

4. Kedisiplinan petugas pelayanan

5. Kecepatan dan ketepatan pelayanan

6. Kepastian jadwal pelayanan

7. KetersediaanAkta Kelahirandi Disdukpencapil

8. Kepastian waktu penyelesaian Akta Kelahiran

Dengan level sigma berada pada kisaran 1,78 - 1,95 sigma.

3. Rekomendasi merupakan tindakan perbaikan dalam proses pelayanan pembuatan Akta Kelahiran dapat dilihat dari masing-masing variabel adalah sebagai berikut : 
Tabel 5. Rekomendasi Perbaikan Kualitas Pelayanan

\begin{tabular}{|c|c|c|}
\hline No & CTQ & Rekomendasi \\
\hline 1 & $\begin{array}{l}\text { Kejelasan } \\
\text { petugas } \\
\text { pelayanan }\end{array}$ & $\begin{array}{l}\text { - Memperbaiki dan meningkatkan sistem pelayanan yang lebih } \\
\text { baik } \\
\text { - Meningkatkan kesadaran tanggung jawab petugas pelayanan } \\
\text { - Memberikan pelatihan dan pengetahuan tentang sistem kerja } \\
\text { dan prosedur kepada petugas } \\
\text { - Memberikan tugas dan tupoksi yang jelas kepada petugas } \\
\text { pelayanan } \\
\text { - Memberikan taudalan dan kedisiplinan dari atasan }\end{array}$ \\
\hline 2 & $\begin{array}{l}\text { Kesopanan } \\
\text { dan } \\
\text { Keramahan } \\
\text { petugas } \\
\text { pelayanan }\end{array}$ & $\begin{array}{l}\text { - Meningatkan kemampuan, kesopanan dan keramahtamahan, } \\
\text { - Meningkatkan sifat menghargai dan menghormati } \\
\text { - Melakukan pengawasan terhadap petugas } \\
\text { - Memperjelas dan menetapkan alur dan prosedur yang optimal } \\
\text { - Memberikan sanksi dan teguran kepada petugas yang } \\
\text { melanggar } \\
\text { - Memberikan pelatihan dan pengetahuan kepada petugas }\end{array}$ \\
\hline 3 & $\begin{array}{l}\text { Kemampuan } \\
\text { petugas } \\
\text { pelayanan }\end{array}$ & $\begin{array}{l}\text { - Mempelajari kembali prosedur pelayanan yang ada } \\
\text { - Melakukan pengawasan dan penilaian terhadap kualitas } \\
\text { pelayanan } \\
\text { - Memberikan reward terhadap yang berprestasi sebagai } \\
\text { tauladan } \\
\text { - Memberikan pelayanan prima kepada masyarakat dalam } \\
\text { kepengurusan } \\
\text { - Memberikan pelatihan dan pengetahuan terutama dalam } \\
\text { memberikan pelayanan } \\
\text { - Memaksimalkan lingkungan tempat pelayanan }\end{array}$ \\
\hline 4 & $\begin{array}{l}\text { Kedisiplinan } \\
\text { petugas } \\
\text { pelayanan }\end{array}$ & $\begin{array}{l}\text { - Konsisten terhadap peraturan dan prosedur yang telah ada } \\
\text { - Memberikan pembinaan, pengarahan dan evaluasi disiplin } \\
\text { petugas } \\
\text { - Memberikan reward terhadap yang berprestasi sebagai } \\
\text { tauladan } \\
\text { - Menerapkan nilai-nilai ketaatan, kesetiaan, kepatuhan, serta } \\
\text { ketertiban dalam menaati prosedur } \\
\text { - Memberikan sanksi disiplin dan teguran kepada petugas yang } \\
\text { melanggar } \\
\text { - Memberikan pelatihan, pengetahuan, pembinaan dan } \\
\text { bimbingan kepada petugas }\end{array}$ \\
\hline 5 & $\begin{array}{l}\text { Kecepatan } \\
\text { dan ketepatan } \\
\text { pelayanan }\end{array}$ & $\begin{array}{l}\text { - Mempelajari kembali prosedur yang ada } \\
\text { - Mengutamakan kepentingan masyarakat } \\
\text { - Bekerja tanpa pamri } \\
\text { - Memaksimalkan perancanaan dan mekanisme kerja } \\
\text { - Melakukan pengawasan terhadap kualitas pelayanan dan } \\
\text { Memaksimalkan kualitas pelayanan } \\
\text { - Memberikan sanksi disiplin dan teguran kepada petugas yang } \\
\text { melanggar } \\
\text { - Memberikan pelatihan dan pengetahuan kepada petugas } \\
\text { pelayanan } \\
\text { - Memberikan reward terhadap yang berprestasi sebagai } \\
\text { tauladan }\end{array}$ \\
\hline
\end{tabular}




\begin{tabular}{|c|c|c|}
\hline 6 & $\begin{array}{l}\text { Kepastian } \\
\text { jadwal } \\
\text { pelayanan }\end{array}$ & $\begin{array}{l}\text { - Bertanggung jawab dengan peraturan yang ditetapkan } \\
\text { - Melakukan pengawasan terhadap kinerja petugas } \\
\text { - Memberikan sanksi disiplin dan teguran kepada petugas } \\
\text { yang melanggar } \\
\text { - Memberikan pelatihan dan pengetahuan kepada petugas } \\
\text { pelayanan } \\
\text { - Memberikan reward terhadap yang berprestasi sebagai } \\
\text { tauladan }\end{array}$ \\
\hline 7 & $\begin{array}{l}\text { Ketersediaan } \\
\text { Akta } \\
\text { Kelahiran } \\
\text { di Disdukpen- } \\
\text { capil }\end{array}$ & $\begin{array}{l}\text { - Menempatkan berkas yang khusus untuk menyimpan berkas } \\
\text { - Meningkatkan sikap tanggung jawab } \\
\text { - Melakukan pengawasan terhadap kualitas pelayanan } \\
\text { - Memberikan pelatihan dan pengetahuan kepada petugas } \\
\text { pelayanan }\end{array}$ \\
\hline 8 & $\begin{array}{l}\text { Kepastian } \\
\text { waktu } \\
\text { penyelesaian } \\
\text { Akta } \\
\text { Kelahiran }\end{array}$ & $\begin{array}{l}\text { - Pengurusan dan prosedur pembuatan Akta Kelahiran } \\
\text { diselesaikan dengan sitem yang akurat } \\
\text { - Memperbaiki kinerja Staf Pencatatan Sipil } \\
\text { - Penyelesaikan pembuatan Akta Kelahiran sesuai dengan } \\
\text { waktu yang telah ditentukan } \\
\text { - Melakukan pengawasan terhadap kualitas pelayanan petugas } \\
\text { - Meningkatkan sikap tanggung jawab terhadap pelayanan } \\
\text { - Melakukan pengawasan terhadap petugas } \\
\text { - Memberikan pelatihan dan pengetahuan kepada petugas }\end{array}$ \\
\hline
\end{tabular}

Sumber : Pengolahan Data, 2015

\section{B. Saran}

Beberapa saran dari penelitian ini adalah sebagai berikut :

1. Untuk penelitian selanjutnya, pada tahap perbaikan/improve bisa juga memakai diagram CEDAC atau dengan menggunakan Failure Mode Effect Analyze (FMEA),

2. Untuk penelitian selanjutnya,pada metode six-sigma sebaiknya dilakukan evaluasi dari usulan perbaikan tersebut dengan menghitung nilai sigma setelah perbaikan dilakukan,

3. Diharapkan penelitian ini dapat memberikan manfaat dalam bentuk perbaikan terhadap kualitas pelayanan di disdukpencapil Kab Pelalawan untuk mencapai pelayanan prima seperti yang diharapkan dan dapat diadopsi oleh disdukcapil daerah lainnya.

\section{DAFTAR PUSTAKA}

[1] Andespa, Roni, 2011,Metode Penelitian Bisnis, Pekanbaru.Penerbit Alaf Riau.

[2] Anggraini, Denny Astrie, 2002, Implementasi Six Sigma untuk Memperbaiki Kinerja Karyawan Tata Usaha Jurusan Teknik Industri, Skripsi Universitas Bung Hatta. Padang.

[3] Dorina, H, 2012, Peningkatan Kualitas Layanan Mahasiswa Dengan Pendekatan Servqual dan Lean Six Sigma, Jurnal Teknik Industri, Universitas Mulawarman.

[4] Efranto, R.Y, 2008, Efaluasi Model Peningkatan Kualitas Pelayanan dengan Pendekatan Servperf Six Sigma, Jurnal Teknik Industri, Institusi Sepuluh November, Surabaya.

[5] Gaspersz, Vincent, 2002, Pedoman Implementasi Program Six-Sigma, Edisi kedua halaman 2-10. Gramedia, Jakarta.

[6] Interview, Tatap muka dengan Ahmad Suhil, Kabid Pencatatan Sipil Kab Pelalawan, 5 November 2014.

[7] James.H Saylor, 1992, Total Integrated Logistics, Gramedia Pustaka. 
[8] Mochamad. C, 2011, Upaya Peningkatan Kualitas Layanan Jasa dengan Menggunakan Metode Six Sigma, Jurnal Teknik Industri Universitas Brawijaya Malang.

[9] Pande, Peter.S.Neumar Peter dan Larry Holp. Cavanagh. Roland. R., 2003, The Sig Sigma Way, edisi kelima halaman 56-197. Penerbit Andi, Yogyakarta.

[10] Pemerintahan daerah Kabupaten Pelalawan, Perda Np 7 tahun 2008 Tentang Susunan Organisas dan Tata Kerja Dinas Daerah Kab Pelalawan.

[11] Priyatno, Duwi, 2011, Buku Saku SPSS,Halaman 97, Yogyakarta. Penerbit Media Kom.

[12] Sarwoto, 1981, Pelayanan efesien, Halaman 120, Ghalia Indonesia, Jakarta. 
